\title{
On Developing Improved Modelling and Scale-up Procedures for Pneumatic Conveying of Fine Powders
}

\author{
Baldeep Kaur ${ }^{1}$, Anu Mittal' ${ }^{2}$, Peter Wypych ${ }^{3}$, S.S.Mallick ${ }^{2 *}$ and Soumendu Jana ${ }^{1}$ \\ ${ }^{1}$ School of Physics and Materials Science, Thapar University, Patiala, Punjab-147004, India \\ ${ }^{2}$ Department of Mechanical Engineering, Thapar University, Patiala, Punjab-147004, India \\ ${ }^{3}$ Faculty of Engineering and Information Sciences, University of Wollongong, NSW-2522, Australia
}

*Corresponding author. Email address: ssmallick@thapar.edu

Telephone number: +91-175-2393080

\begin{abstract}
Pneumatic transport of fine powders in fluidized dense-phase mode is becoming increasingly popular in various industries, such as power, chemical, cement, refinery, alumina, pharmaceutical, limestone, to list a few, because of the reasons of reduced gas flow rate and power consumption, decreased conveying velocities, improved product quality control, reduced pipeline sizing and wear rate, increased workplace safety etc. For the reliable design of a pneumatic conveying system, it is important to accurately predict the total pipeline pressure drop. However, accurate prediction of pressure drop from an improved understanding of the fundamental transport mechanism of fluidized dense-phase flow condition has only made limited progress till now because of the highly concentrated and turbulent nature of the gas-solids mixture. Power plant fly ash (median particle diameter: $30 \mu \mathrm{m}$; particle density: $2300 \mathrm{~kg} / \mathrm{m}^{3}$; loose-poured bulk density: $700 \mathrm{~kg} / \mathrm{m}^{3}$ ) was conveyed through different pipelines (69 mm I.D. $\mathrm{x}$ 168 m long; 105 mm I.D. x 168 m long; 69 mm I.D. x 554 m long). 8 different fly ash samples were tested in a fluidizing column for their deaeration characteristics and fluidized bulk densities
\end{abstract}


were determined. Governing equations of flow for the dense-phase pneumatic conveying system of fine powders were solved using Runge-Kutta-Fehlberg (RKF45) method for different fluidized bulk densities of fly ash and air flow rates. The results have shown that the particle and actual gas velocities and the ratio of the two velocities increase in the direction of flow, while a reverse trend was apparent for the solids volumetric concentration. The results were compared against the predictions obtained using existing empirical relations for particle velocity. To develop an improved model for solids friction factor, an existing reliable pure dilute-phase model has been modified for dense-phase flow condition by incorporating sub-models for particle to actual gas velocity and impact and solids friction factor. The developed solids friction factor model was validated by using it to predict the total pipeline pressure drops for larger and longer pipelines and by comparing the experimental and predicted pneumatic conveying characteristics. The results have shown improved reliable predictions and that the model is capable of addressing the gradual transition of flow mechanism from dense- to dilute-phase. The accuracy of prediction is similar (in fact better in certain scale-up cases) when compared to a recently developed twolayer based model (developed by some of the authors). The results demonstrate the importance of incorporating particle and actual gas velocity terms in the model of solids friction factor instead of the prevailing techniques that overly depend on using superficial gas velocities.

Keywords: pneumatic conveying, dense-phase, fine powders, solids friction, scale-up validation 


\section{Introduction}

The dense-phase pneumatic transport of fine powders is preferred in several industries, such as coal fired thermal power plants, chemical, pharmaceutical, petrochemical plants, cement, food, etc. over conventional dilute-phase (or suspension flow) due to the reasons of high solids to gas mass ratio, low gas flow requirement (i.e. smaller compressor and savings in operating power), smaller size of pipes and fittings, reduced conveying velocity resulting in lowering of wear rate of pipelines and bends, decreased rate of product attrition, reduced size of solids-gas separation equipment, etc. $[1,2]$. In this mode of transport, the gas velocities are kept sufficiently low (below the saltation velocities), so that the conveying takes place in a non-suspension mode [1, 2]. Typically, the Geldart Group A type fine powders that have good air retention capabilities, such as fly ash, cement, pulverized coal, etc., are good candidates for dense-phase mode of conveying [3]. Designing a dense-phase pneumatic conveying system includes accurate prediction of the total pipeline pressure loss and the minimum air flow rate requirement to ensure flow blockage does not take place. Under-prediction of pressure drop at the design stage would result in reduced material flow rate, whereas over-prediction of pressure drop would result in increased initial and operating costs (due to unnecessary higher conveying velocity). The pressure loss for solids-gas flow through a straight horizontal pipe section can be expressed using equation 1, as given by Barth [4].

$\Delta \mathrm{P}=($ 
Equation 1 considers the pressure losses due to the gas and solids phases separately. Weber [5] employed this expression (equation 1) for coarse particles in dilute-phase flows. However, various researchers $[2,6$ to 10$]$ have subsequently used this representation to estimate the pressure drop for the dense-phase pneumatic transport of fine powders, such as fly ash, pulverized coal, ESP dust, etc. for horizontal straight pipes. In this model, while all other terms can be calculated relatively easily using well established gas only friction factor formula [11], accurate prediction of solids friction factor has been a difficult task due to the limited fundamental understanding of the flow mechanisms of powdered beds. The term solids friction factor is a combined representation of loss of energy due to solids to gas, solids to solids, and solids to pipe wall interactions [1,2]. Whereas, more fundamental modelling methods based on powder mechanics have been developed for certain products and modes of flows, such as lowvelocity slug-flow of granular products [12 to 14] or the dilute-phase flow of bulk solids (for which the suspension flow mechanics can be considered to be applicable with a fair accuracy) [15], the modelling of solids friction factor for the dense-phase conveying of fine powders has been a far more difficult problem to be solved at a similar level of detail. This is due to the highly turbulent and complex nature of dense phase mode of conveying [2], which makes it very difficult to link the particle and bulk properties during actual flow conditions. Because of the limited progress that has been achieved so far towards fundamentally understanding the transport mechanisms and modelling of solids friction factor, empirical power function based models have been popularly used over the years by several investigators [2, 6 to 10], using dimensionless numbers, as given by equations 2 and 3 : 
Previous investigation [2] has demonstrated that the above formats of modelling solids friction factor can unexpectedly result in grossly inaccurate predictions under significant scale-up conditions of pipeline length and diameter. Very recently, some of the authors have provided a new two-layer based model format for solids friction factor [16], which includes separate contributory terms for the non-suspension and suspension flows. The format is provided in the following:

In the above model, the first term, $K($ contribution $[10,11,16]$, whereas the second term, dilute-phase contribution $[15,16] . \beta_{0}$ is given as $w \quad V$. This portion has been taken from a pure dilute-phase model, known as "Weber A4" model [15]. This model (Weber A4) has been reported [2, 15] to provide good predictions for dilute-phase flow for different pipeline configurations. This model separates the solids friction factor into losses contributed due to the impact and friction between particle to air/particle/pipe-wall and that due to keeping the particles in suspension. $\tau_{1}$ and $\tau_{2}$ represent coupling factors, whose values depend on the Froude number (based on superficial air velocity). The two-layer model format was validated for two different fly ash samples, ESP dust and cement under significant scale-up conditions of pipeline diameter and length (viz. pipe internal diameters of 69, 80, $105 \mathrm{~mm}$ and lengths of 168, 254, 407 and 554 m). The results indicated that the two-layer model could provide better reliable scale-up 
predictions than other previously known models. The predicted pneumatic conveying characteristics provided relatively better ' $U$ '-shaped curves that possibly represent the dense- to dilute-phase flow transition [2]. In spite of such recent developments, the authors are of the opinion that very little progress has been achieved so far towards fundamentally understanding the transport mechanism of dense-phase solids-gas flow of fine powders and the solids friction factor models rely heavily on the empirical approaches involving the use of dimensionless numbers. The existing models [2, 6 to 10,16] for solids friction factor use "superficial gas velocity", instead of actual gas velocity. Actual gas velocity can be considered to be adequately represented by superficial gas velocity for dilute-phase flow, where the pipe volume occupied by the particles is minor compared to the rest of the pipe volume available for gas flows. However, for dense-phase type flows, due to higher concentration of solids, the lack of cross section available for the flow of gas-phase should not be ignored. Also, most of the existing models (e.g. equations 2 and 3) do not address particle velocity and the slip velocity (the difference between gas and particle velocities) and rely on the superficial velocity of the gas. The authors consider that it would be prudent to include a particle velocity term in modeling solids friction factor. The aim of this paper is to solve governing equations for gas-solids flows (under dense-phase condition) for important parameters such as particle and actual gas velocities and make use of these parameters in developing reliable scale-up validated model for solids friction factor. Some studies using numerical methods have been carried out in recent times [17, 18]. One-dimensional model including particle size distribution was developed [19] to simulate the pneumatic conveying of fine powders through straight pipelines. A set of one-dimensional flow equations were solved in order to predict the flow parameters at the inlet of the pipeline by using the experimental data as initial conditions at the exit of the pipeline. Using the developed model, 
pressure drop values through the pipeline were predicted and compared with experimental data. Predicted values were found to be in good agreement with the experimental data. One of the key aspect that requires attention is particle velocity [20]. Effects of material properties such as friction and restitution coefficients of particles on flow behaviors in terms of particle flow pattern, gas pressure drop, solid concentration, particle velocity and transition of flow regime were studied [21]. However, such studies have considered particle velocity relation applicable only for dilute-phase (and not applicable for the dense-phase flow), which would tend to provide significant over-estimation of particle velocity when applied to dense-phase cases. The present paper attempts to provide solution for particle velocity for the dense-phase flow condition. It must be also noted that experimental measurement of particle velocity during actual flow condition is a difficult task and in the knowledge of the authors, very little research has been conducted to develop a reliable measurement method. Sight glass observations only provide limited information due to the sticking of the powders on the inner surface of glass. Most of the existing models (majorly empirical) for particle velocity are applicable for coarse particles being transported in dilute-phase [21].

\section{Experimental Setup}

Power station fly ash was conveyed from dense- to dilute-phase through pipelines of different lengths and diameters (i.e. 69 mm I.D. x 168 m long, 105 mm I.D. x 168 m long, 69 mm I.D. x $554 \mathrm{~m}$ long) at the Bulk Materials Handling Laboratory of University of Wollongong, Australia.

The fly ash was conveyed with different air and solids mass flow rates. Physical properties of the 
fly ash and pipeline conditions are given in Table 1. Particle size distributions were measured using laser diffraction method. The value of terminal settling velocity for the fly ash particle is also included in Table 1.

Table 1: Physical properties of the fly ash conveyed

Schematic diagram of the $69 \mathrm{~mm}$ I.D. x $168 \mathrm{~m}$ long pipeline is shown in Figure 1.

Figure 1: Layout of the $69 \mathrm{~mm}$ I.D. $x 168 \mathrm{~m}$ test rig (for fly ash)

The test rig comprised a $0.5 \mathrm{~m}^{3}$ bottom-discharge type blow tank feeding system. Pipes and bends used in the pilot plant were made of mild steel. The pipeline consisted of 5 bends and a vertical lift of $7 \mathrm{~m}$ height. All bends were of $1 \mathrm{~m}$ radius of curvature and $90^{\circ}$ angle. Ingersoll Rand dieselpowered Model P375-WP, $10.6 \mathrm{~m}^{3} / \mathrm{min}$ free air delivery screw compressor was used to supply compressed air at a maximum pressure of approximately $800 \mathrm{kPa}$-g. Five static pressure transducers were used along the pipeline (P8 to P12) to measure static pressure in the horizontal straight sections of pipeline. The static pressure transducers had the following specification: manufacturer: Endress and Hauser, model: Cerabar PMC133, pressure range: 0-6 and 0-2 bar-g, maximum pressure: 40 bar (absolute), current signal: 4 to $20 \mathrm{~mA}$. These transducers were strategically installed not to get affected by the flow disturbances caused by the bends. The P8 transducer measured the total pipeline pressure drop and P9 to P12 measured the static pressures along the pipeline. A receiver bin of capacity $6 \mathrm{~m}^{3}$ was installed with a pulse-jet type dust filter on 
top of the blow tank. All other required instruments, such as PRV (pressure reducing valve), flow meter, NRV (non-return valve), flow control valve, pressure gauge and load cells (shear beam type) were suitably placed. Calibrations of the transducers, load cells and flow meter were performed using a standardized calibration procedure [2]. A portable PC compatible data logger (Datataker 800 of Data electronics) was used (having 24 channels) to record the electrical output signals from the load cells, pressure transducer and flow meters.Detailed description of the test setup and conveying program are provided in [2]. Initial conveying experiments were performed with medium ranges of air flows. Then the air flow rate was gradually reduced to achieve dense-phase flow. The air flow rate was then further reduced till large pressure fluctuations indicating unstable flow condition appeared leading to pipeline blockage. The air flow was subsequently increased to high velocities (dilute-phase) to generate complete pneumatic conveying characteristics from dense-to-dilute-phase region covering a wide range of air and solids flow rates. Certain tests were repeated to confirm repeatability of test results. A test facility was developed at the Laboratory for Particle and Bulk Solid Technologies, Thapar University to conduct fluidization and de-aeration tests. A schematic of the test facility is provided in Figure 2.

Figure 2: Fluidization and de-aeration chamber

A side channel centrifugal type blower $\left(0.75 \mathrm{~kW}\right.$ and maximum air delivery of $\left.145 \mathrm{~m}^{3} / \mathrm{h}\right)$ was used to supply air to the fluidization chamber. A variable frequency drive was attached to the blower to control the air flow rate by changing the frequency. Two rotameters were used in parallel combination in the air line to measure the air flow rate within appropriate flow ranges. The regulating valves were installed in the air line to obtain different air flow rates. A mild steel 
plenum chamber having $102 \mathrm{~mm}$ of internal diameter and height of $150 \mathrm{~mm}$ was attached to the fluidization column for uniform air distribution. A porous membrane having $5 \mu \mathrm{m}$ porosity was placed between the plenum chamber and fluidizing column to support the powders. The fluidizing column was fabricated of acrylic tube for better visibility of the fluidizing behavior of powders. Five pressure tappings were installed at equal distances from each other along the height of the column to measure pressure drop across the bed material. The bed height was measured by attaching a centimeter scale on the column. A set of manometers was used to measure the pressure of each tapping. A high speed digital camera with 60 frames per second capturing speed was used to visualize the fluidization and de-aeration behavior of powders. The fluidization and de-aeration tests were carried out on 8 different fly ash samples with varying particle sizes. Table 2 gives the key physical properties of the different fly ash samples. Fluidized bulk density values were obtained from the maximum height (and hence volume) achieved (measured by the scale) at the onset of fluidization (i.e. corresponding to minimum fluidization condition). Fluidized bulk density $\left(\rho_{f l}\right)$ values were determined by dividing the expanded volume of aerated fly ash (corresponding to minimum fluidization condition) by the mass of powders. De-aeration characteristics of powders were determined by noting the bed height (from maximum to gradually decreasing) and pressure variation with time after turning off the air supply. Terminal settling velocities, ratio of fluidized to loose-poured bulk densities and particle Froude number values for different fly ash samples are provided in Table 2. 
Table 2: Physical properties of different fly ash samples for fluidization and deaeration tests

Figure 3 shows the plot of ratio of fluidized to loose poured bulk densities for different particle Froude number values.

Figure 3: Model development for fluidized bulk density of fly ash

A linear trend could be observed for the fly ash samples with $R^{2}$ value of 0.95 (indicating good fit). The relationship is expressed as:

$\frac{\rho_{\mathrm{fl}}}{\rho_{\mathrm{b}}}=0.0235 F r_{\mathrm{s}}+0.344$

Using the above expression (equation 5), the fluidized bulk density of the given fly ash (Table 1) is $\approx 300 \mathrm{~kg} / \mathrm{m}^{3}$. 


\section{One dimensional model for solids-gas flow}

For developing the governing equations, the following assumptions have been made:

- The flow is one-dimensional (x-direction, i.e. in the direction of bulk flow).

- The composition of solids-gas mixture in a finitely small control volume is uniform, well mixed and there is no concentration gradient of particles across the pipe diameter.

- The flow is steady.

- The system is isothermal and the gas phase obeys the ideal gas equation of state.

- There is no mass and heat transfer between the phases.

For developing the energy equation, energy balance across a control volume is as given below:

Figure 4: Energy interactions across a control volume

Net accumulation of pressure and shear energy in x-direction:

$=A P u_{a}-A\left[\left(P+\frac{d P}{d x} \Delta x\right)\left(u_{a}+\frac{d u_{a}}{d x} \Delta x\right)\right]-\left[F_{a}\left(u_{a}+\frac{d u_{a}}{d x} \frac{\Delta x}{2}\right)+F_{s}\left(u_{s}+\frac{d u_{s}}{d x} \frac{\Delta x}{2}\right)\right]$

Net accumulation of kinetic energy in $\mathrm{x}$-direction

$=\frac{1}{2} m_{a} u_{a}^{2}+\frac{1}{2} m_{s} u_{s}^{2}-\frac{1}{2} m_{a}\left(u_{a}+\frac{d u_{a}}{d x} \Delta x\right)^{2}-\frac{1}{2} m_{s}\left(u_{s}+\frac{d u_{s}}{d x} \Delta x\right)^{2}$ 
Neglecting higher order terms and considering there is no net acummulation of energy within the control volume under steady state condition, the following energy equation is obtained:

$P \frac{d u_{a}}{d x}+u_{a} \frac{d P}{d x}+u_{a} f_{a}+u_{s} f_{s}+\rho_{a} \varepsilon_{a} u_{a}^{2} \frac{d u_{a}}{d x}+\rho_{s} \varepsilon_{s} u_{s}^{2} \frac{d u_{s}}{d x}=0$

The conservation of momentum equation for the solids-gas flows is written as:

$$
\begin{aligned}
& {\left[\left(\rho_{a} \varepsilon_{a} A u_{a}\right)\left(u_{a}+\frac{d u_{a}}{d x} \Delta x\right)-\left(\rho_{a} \varepsilon_{a} A u_{a}\right) u_{a}\right]+\left[\left(\rho_{f l} \varepsilon_{s} A u_{s}\right)\left(u_{s}+\frac{d u_{s}}{d x} \Delta x\right)-\left(\rho_{f l} \varepsilon_{s} A u_{s}\right) u_{s}\right]} \\
& \quad=\left[P A-\left(P+\frac{d P}{d x} \Delta x\right) A\right]-F_{a}-F_{s}
\end{aligned}
$$

Dividing both sides of equation (8) by elemental volume (A $\Delta \mathrm{x})$,

$\varepsilon_{a} \rho_{a} u_{a} \frac{d u_{a}}{d x}+\varepsilon_{s} \rho_{f l} u_{s} \frac{d u_{s}}{d x}+\frac{d P}{d x}=-f_{a}-f_{s}$

Conservation for mass for the gas-phase and solids-phase are represented separately by equations 11 and 12 , respectively.

$$
\begin{aligned}
& \frac{d}{d x}\left(\varepsilon_{a} \rho_{a} u_{a}\right)=0 \\
& \frac{d}{d x}\left(\varepsilon_{s} \rho_{f l} u_{s}\right)=0
\end{aligned}
$$

Volume fractions for the gas and solid phases are related by:

$\varepsilon_{a}+\varepsilon_{s}=1$ 
Similar expression as above was also provided in $[17,18]$. In further research work, mathematical model for fluidized dense phase including particle size distribution was also presented [19]. In equations 6 to 13, fluidized bulk density has been considered as the representative solids density considering the flow nature of the fluidized dense-phase flow. The system of equations (equations 8,10 to 12 ) has been solved for the four variables $u_{s}, u_{a}, \varepsilon_{s}$ and $P$. Firstly, the conservation equations (equations 8, 10 to 12) have been transformed into coupled first order ordinary differential equations (equations 14 to 17), which show the evolution of an individual parameter under study. The fluidized bulk density for the solids phase has been considered to be constant term in the system; therefore, the spatial variation of the parameter $\rho_{f l}$ vanishes. The derived equations are represented in the following form:

$$
\begin{aligned}
& \frac{d u_{s}}{d x}=\frac{u_{s}}{\varepsilon_{s}\left(\rho_{f l} u_{s}^{2}\left(u_{s}-u_{a}\right)-\frac{u_{a} P}{\left(1-\varepsilon_{s}\right)}\right)}\left[-\left(u_{s}-u_{a}\right) f_{s}+\frac{u_{a} P}{\rho_{a}} \frac{d \rho_{a}}{d x}\right] \\
& \frac{d u_{a}}{d x}=-\frac{u_{a}}{\rho_{a}} \frac{d \rho_{a}}{d x}-\frac{u_{a}}{\left(1-\varepsilon_{s}\right)\left(\rho_{f l} u_{s}^{2}\left(u_{s}-u_{a}\right)-\frac{u_{a} P}{\left(1-\varepsilon_{s}\right)}\right)}\left[-\left(u_{s}-u_{a}\right) f_{s}+\frac{u_{a} P}{\rho_{a}} \frac{d \rho_{a}}{d x}\right] \\
& \frac{d \varepsilon_{s}}{d x}=-\frac{1}{\left(\rho_{f l} u_{s}^{2}\left(u_{s}-u_{a}\right)-\frac{u_{a} P}{\left(1-\varepsilon_{s}\right)}\right)}\left[-\left(u_{s}-u_{a}\right) f_{s}+\frac{u_{a} P}{\rho_{a}} \frac{d \rho_{a}}{d x}\right] \\
& \frac{d P}{d x}=-f_{a}-f_{s}+\left(1-\varepsilon_{s}\right) u_{a}^{2} \frac{d \rho_{a}}{d x}+\frac{\left(\rho_{a} u_{a}^{2}-\rho_{f l} u_{s}^{2}\right)}{\left(\rho_{f l} u_{s}^{2}\left(u_{s}-u_{a}\right)-\frac{u_{a} P}{\left(1-\varepsilon_{s}\right)}\right)}\left[-\left(u_{s}-u_{a}\right) f_{s}+\frac{u_{a} P}{\rho_{a}} \frac{d \rho_{a}}{d x}\right]
\end{aligned}
$$

Equations 14 to 17 present the evolution of the parameters $u_{s}, u_{a}, \varepsilon_{s}$ and $P$, respectively, with respect to the spatial co-ordinate $x$, i.e., along the length of the pipeline. The pipeline has been 
divided into several straight pipe sections (Figure 1). Long pipeline sections have been divided into 2 sections. The different values of ' $x$ ' thus obtained on the horizontal pipe for the purpose of study in this paper are: $3.26,24.62,60.84,81.31,98.78$ and $129 \mathrm{~m}$ (starting from the blow tank location). For each small section, a set of coupled ordinary differential equations (i.e., equations 14 to 17 ) have been solved numerically using MATLAB's ode45 solver, which is based on the fourth-fifth-order Runge-Kutta-Fehlberg (RKF45) method [22, 23]. Initial conditions for the parameters $u_{s}, u_{a}, \varepsilon_{s}$ and $P$ have been taken from the corresponding experimental data. Values of $\mathrm{f}_{\mathrm{s}}, \mathrm{f}_{\mathrm{a}}, \rho_{\mathrm{a}}$ and $\frac{d \rho_{a}}{d x}$ have been obtained from the experimental data of conveying fly ash through the $69 \mathrm{~mm}$ I.D. $x 168 \mathrm{~m}$ long test rig. In order to determine the initial value of $\mathrm{u}_{\mathrm{s}}$, the following relationship has been used considering when the product is discharged from the blow tank, with the aerated mixture occupying the full cross section of the pipe. The level of occupancy decreases subsequently in the direction of flow.

$u_{s}=\frac{m_{s}}{A \rho_{f l}}$

Numerically determined values of parameters obtained at the end of the first pipe section serve as the initial conditions for the successive section. This practice has been followed upto the exit point of the pipeline. Values of the parameters $u_{s}, u_{a}, \varepsilon_{s}, u_{s} / u_{a}$ and $P$ have been determined at the initial and final point of each section and from this, results corresponding to the mid point values (at $\mathrm{x}=3.26,24.62,60.84,81.31,98.78$ and $129 \mathrm{~m}$ ) were obtained. The results (variation of $u_{s}, u_{a}, u_{s} / u_{a}$ and $\varepsilon_{s}$ along the length of pipe from $x=3.26$ to $129 \mathrm{~m}$ ) are provided in the following Figures 5 to 8 . The results correspond to solids mass flow rate of $19 \mathrm{t} / \mathrm{h}$, two different air mass flow rates $(0.04$ and $0.08 \mathrm{~kg} / \mathrm{s})$ and fluidized bulk densities of 300 and $400 \mathrm{~kg} / \mathrm{m}^{3}$. The 
$300 \mathrm{~kg} / \mathrm{m}^{3}$ fluidized bulk density corresponds to the conveyed fly ash sample (as per equation 5). An additional set of results for $400 \mathrm{~kg} / \mathrm{m}^{3}$ have been produced and superimposed on Figures 5 to 8 to demostrate the effects of variation of results for the difference in fluidized bulk densities.

Figure 5: Variation of particle velocity for different air flows and fluidized bulk densities along the flow direction

Figure 6: Variation of actual air velocity for different air flows and fluidized bulk densities along the flow direction

Figure 7: Variation of ratio of particle to actual air velocity for different air flows and fluidized bulk densities along the flow direction

Figure 8: Variation of solids volumetric concentration for different air flows and fluidized bulk densities along the flow direction

Figure 5 shows that for all cases, there is an overall increase in the values of particle velocities along the direction of flow (with an increase in actual gas velocity, see Figure 6). Higher gas flow rates have resulted in larger increment in the values of particle velocity. Overall, larger particle velocity values were obtained for lower fluidized bulk densities. Figure 6 shows that for all cases, there is an overall increase in the values of actual gas velocities along the direction of flow. It can be seen from Figure 7 that the values of the ratio of particle to gas velocities increase 
in the direction of flow, indicating that the rate of increase in gas velocity (due to gas expansion) is more dominating over the corresponding rise in velocity of the particles. There is a larger slip beween the gas and solids phases in the direction of flow. It can be observed from Figure 7 that there is a sharp rise in the value of the solids to gas velocity ratio after the closely coupled bends (see Figure 1). This could be due to the considerable drop in gas pressure due to flow through the closely coupled bend and the associated effect of gas expansion. Solids volumetric concentration decreases along the direction of flow (Figure 8) indicating there is a gradual transition of dense to dilute-phase condition prevailing inside the pipeline. There has been considerable amount of work in experimentally measuring and developing empirical models for the coarser particles being transported in dilute-phase. Wei et al. [20] has provided a comprehensive list of such models. Wei et al. [20] provided a model given by Klinzing et al. [24] that has been reported to be applicable in the particle size range of 67 to $900 \mu \mathrm{m}$. The Hong and Shen [25] model has been reported [20] to be applicable for "High solid-gas ratio, fine powder". It has been considered in this paper that as the Klinzing et al. [24] and Hong and Shen [25] models are reportly [20] applicable for particles that are close to the fine powder range, hence these two models will be used to compare the results obtained using numerical studies (Figure 5) to those obtained using these empirical relations. The emprical models of Klinzing at al. [24] and Hong and Shen [25] are provided by equations 19 and 20, respectively. Wei et al. [20] has used the term ' $U_{g}$ ' in place of ' $u_{a}$ ' and mentioned ' $U_{g}$ ' as the "superficial gas velocity". The superficial gas velocity term could be adequately representing the actual velocity for dilute-phase conveying. However, these two terms can have considerably different values for dense-phase flows (where the actual gas velocity values are considerably higher than the superfical values due to a substantial amount of solids volume occupancy in the pipeline). Due to such potential ambiguity, predictions have been 
made using equations 19 and 20 by considering ' $u_{a}$ ' as both actual gas velocity and superficial gas velocity. Results of comparison (between the numerical and empirical models) are provided in Figure 9. One of the limitaions of the model given by equation (19) seems to be that the numerical contribution of the $\mathrm{w}_{\mathrm{fo}} 0.71$ term appears quite smallcompared to the ' $u_{a}$ ' term. Also, the model does not reflect any solids loading ratio (or equivalent) term. This seems to indicate that the Klinzing et al. [24] model is inherently suitable for only dilute-phase condition. On the contrary, the Hong and Shen [25] model uses particle density term. For the fluidized dense-phase flow of particles, a bulk density term would have been more appropriate.

$$
\begin{aligned}
& \mathrm{u}_{\mathrm{s}}=\left(\mathrm{u}_{\mathrm{a}}-\mathrm{W}_{\mathrm{fo}} 0.71\right) D^{0.019} \\
& \mathrm{u}_{\mathrm{s}}=\mathrm{u}_{\mathrm{a}}\left[1-0.533\left(\frac{1000 \rho_{\mathrm{a}}}{\rho_{\mathrm{s}}}\right)^{1.093}\left(\frac{\mathrm{D}}{100 \mathrm{~d}_{\mathrm{p}}}\right)-0.721\right]
\end{aligned}
$$

Figure 9: Comparison of prediction of particle velocity, numerical versus model predictions,

$$
\mathrm{m}_{\mathrm{s}}=19 \mathrm{t} / \mathrm{h}, \mathrm{m}_{\mathrm{a}}=0.04 \mathrm{~kg} / \mathrm{s}, \rho_{\mathrm{fl}}=300 \mathrm{~kg} / \mathrm{m}^{3}
$$

It can be seen from Figure 9 that the particle velocity values obtained using the numerical model lie in between the two sets of prediction values. Both the empirical models have provided similar sets of results (under identical conditions of "actual air velocity" or "superficial air velocity"). Using the numerical results obtained for the ratio of particle to actual gas velocity $\left(\frac{\mathrm{u}_{\mathrm{s}}}{\mathrm{u}_{\mathrm{a}}}\right)$ (as provided in Figure 7) for 19 and $9 \mathrm{t} / \mathrm{h}$ of solids slow rates and for $0.04,0.08$ and $0.12 \mathrm{~kg} / \mathrm{s}$ of gas flow rates, the following model (equation 21) has been obtained using the multiple regression method. Equation (21) is in power function format, where the ratio of particle to actual gas 
velocity has been represented by solids loading ratio and dimensionless velocity terms quite well. The high value of $R^{2}\left(R^{2}=0.95\right)$ indicates good fit. This relation has been used in the following section to model solids friction factor.

$$
\frac{u_{s}}{u_{a}}=10^{-3.227} m^{* 1.212}\left(\frac{w_{f o}}{V}\right)^{-0.385}, R^{2}=0.95
$$

\section{Modeling solids friction factor and scale-up validation}

To develop an accurate model for solids friction factor for the fluidized dense-phase flow, a reliable pure dilute-phase model, known as "Weber-A4" model [15], has been considered as the starting point. This model has been reported to result in accurate predictions for dilute-phase flow for different pipeline configurations and products $[2,15]$.The Weber-A4 model separates the solids friction pressure drop into two components: losses due to impact and friction between particleparticle/air/pipe wall and those due to keeping the particles in suspension. The model is given by equation (22).

$\lambda_{\mathrm{s}}=\lambda_{\mathrm{s}}{ }^{*} \frac{C}{V}+\frac{2 \frac{w_{f o}}{V}}{\frac{C}{V} F r^{2}}$

where, $\lambda_{s}{ }^{*}$ represents the impact and friction component corresponding to dilute-phase condition and is taken as a constant [15]. Typically, for very dilute-phase flows, the $\mathrm{C} / \mathrm{V}$ values have been assumed to be approaching unity $[1,2,16]$, especially for fine powders. This seems to be a reliable assumption for very dilute phase flows [1]. It is not apparent from [15] that whether the 
gas velocity term in equation (22) corresponds to superficial gas velocity or actual gas velocity. However, for pure dilute-phase flows, it can be considered that the superficial gas velocity approaches actual gas velocity (due to the low volumetric occupancy of particles in the pipeline). Using steady state experimental pressure drop data obtained from P11-P12 straight pipeline section and using $\frac{C}{V}=\frac{u_{s}}{u_{a}}$ values obtained from equation (21) for different experimental conditions, different values of $\lambda_{s}{ }^{*}$ have been obtained. Subsequently a model for $\lambda_{s}{ }^{*}$ has been generated using Volumetric Loading Ratio (VLR) and dimensionless velocity terms, where VLR is expressed as:

$V L R=\left\{\left(m_{s} / \rho_{s}\right) /\left(m_{a} / \rho_{a}\right)\right\}$

Rautiainen et al. [26] employed solids volume fraction to model pneumatic conveying of solids and stated that the solids volume concentration will influence the slip velocity of particles, which is a crucial parameter to represent pressure drop of solids-gas flows. The occupied volume of solids will affect the free gas path, because the gas would need to follow the circuitous path available between clusters of solid particles. This non-linear gas path would contribute to the pressure drop of the gas-phase. Bosse et al. [27] concluded that "two-way coupling" is applicable for dense-phase flow. In this flow condition, the gas and fine solids will influence the turbulence of each other and vorticity dynamics of flow. Huber and Sommerfield [28] proposed that the finer particles caught in eddies would have velocities and flow paths similar to the gas phase. Therefore, it appears that the volume fraction of solids would influence the turbulence pattern of the gas-phase and hence VLR has been considered as an appropriate dimensionless parameter to model solids impact and friction factor in the present paper. To describe the flow mode (non- 
suspension or suspension), another dimensionless term $\mathrm{w}_{\mathrm{f} 0} / \mathrm{V}$ has been used in the model. Using these dimensionlessparameters, the following model for $\lambda_{s}{ }^{*}$ has been developed using multiple regression method. The high value of $R^{2}$ indicates good fit.

$\lambda_{s}^{*}=10^{-0.223} V L R^{-1.172}\left(\frac{w_{f o}}{V}\right)^{1.441}, \mathrm{R}^{2}=0.94$

The Volumetric Loading Ratio (VLR) term has been used in the expression of impact and friction factor for solids, which uses gas density term (equations 23 and 24). This also addresses the issue of gas compressibility. The values of solids friction factor $\left(\lambda_{s}\right)$ are determined using the equation (22), where $\lambda_{s}{ }^{*}$ and $\frac{C}{V}$ or $\frac{u_{s}}{u_{a}}$ are to be obtained using the models given by equations (24) and (21), respectively. The newly develop model for solids friction factor has been validated for longer and larger pipelines (69 mm I.D. $\times 168 \mathrm{~m}$ long, $105 \mathrm{~mm}$ I.D. $\times 168 \mathrm{~m}$ long and $69 \mathrm{~mm}$ I.D. $\times 554 \mathrm{~m}$ long, thus for proper length and diameter scale-up conditions) for different solids and air flow rates by comparing the predicted pneumatic conveying characteristics against the experimental plots. The results are provided in Figures 10 to 12. To determine the total pipeline pressure drop, an iterative program (using SOLVER and MACRO in Microsoft Excel 2007) has been developed by segmenting the entire pipeline into several smaller straight pipe sections and bends. The program commences from the exit point of the pipe and progressively estimates pressure losses in different pipe sections up to the blow tank. Chambers and Marcus [29] models have been employed to estimate the pressure drops due to initial acceleration, verticals and bends, as given by equations 25 to 27 .

Acceleration loss $\quad: \quad \Delta P_{\text {accel }}=\rho_{a} V^{2}\left(1+2 m^{*} C / V\right) / 2$ 
Vertical loss

$$
\text { : } \quad \Delta P_{V}=m^{*} \rho_{a} g L_{V} V / C
$$

Bend loss

$$
\text { : } \quad \Delta P_{b}=N B\left(1+m^{*}\right) \rho_{a} V^{2} / 2
$$

Particles decelerate at the exit of the bends and the subsequent reacceleration of particles is the main cause of pressure drop through the bend. To address the post bend conditions, the air density and velocity terms used in equation (27) correspond to the bend exist condition (i.e. gas density and velocity at bend exist). This is as per [6] and was subsequently used in [2]. To evaluate the relative accuracy of the newly developed model, predictions using a recent twolayer based model (developed by some of the authors) and that obtained using the original Weber A4 model [15] have been superimposed on Figures 10 to 12. For the purpose of completeness, the two-layer model of Setia et al. [16] is provided below by equation (28). The value of $\lambda_{\mathrm{s}}{ }^{*}$ was taken as 0.0043 for the two layer model of Setia et al. [16] and Weber A4 model [15]. To further address the issue of gas compressibility, the entire pipeline was divided into smaller sections while calculating the total pipeline pressure drop and the calculations were initiated from the last section of the pipeline (with known exit pressure of zero gauge). As per the model for solids friction given by equations (22) and (24), solids friction changes continuously with an increase in gas velocity, indicating a gradual change in flow mechanisms with the rise in superficial gas velocity. This is in accord to the findings of Kuang et. al [30], who attempted to investigate gassolid flow through inclined pipeline using combined approach of computational fluid dynamics and the discrete element method (CFD-DEM). Plots of volumetric force and energy dissipation were shown for increasing superficial gas velocity. It was concluded that dominant frictional effects mechanistically depend on the mode of flow, such as: in the slug flow regime, the energy dissipation is mainly due to particle-particle collisions; particle-fluid energy dissipation is 
dominant in stratified flow regime and the dispersed flow regime is characterized by fluid-wall viscous energy dissipation. In this paper, during calculations of the total pipeline pressure drops, for the small pipe section, the solids frictional forces were considered to be of fixed value (corresponding to the mid section conditions). However, the values of solids friction factor got changed from section to section (generally lowest at the pipe exit section and highest at the feed point section, i.e. generally following a decreasing trend from the beginning or feed point zone of the pipe to the exit zone of pipeline).

Figure 10: Scale-up evaluation for solids friction factor model

$$
\mathrm{m}_{\mathrm{s}}=19 \mathrm{t} / \mathrm{h}, \mathrm{D}=69 \mathrm{~mm}, \mathrm{~L}=168 \mathrm{~m}
$$

Figure 11: Scale-up evaluation for solids friction factor model

$$
\mathrm{m}_{\mathrm{s}}=28 \mathrm{t} / \mathrm{h}, \mathrm{D}=105 \mathrm{~mm}, \mathrm{~L}=168 \mathrm{~m}
$$

Figure 12: Scale-up evaluation for solids friction factor model

$$
\mathrm{m}_{\mathrm{s}}=11 \mathrm{t} / \mathrm{h}, \mathrm{D}=69 \mathrm{~mm}, \mathrm{~L}=554 \mathrm{~m}
$$

It has been seen during the test program [2] that stable conveying was possible starting at $F r_{i}=4$ and 3 for the $168 \mathrm{~m}$ pipes and $554 \mathrm{~m}$ pipelines, respectively. Below this range, flow instabilities and ultimately flow blockages were found to occur [2]. Hence, predictions using the new model have been limited to $F r_{i}=3$ and 4 . It can be seen in Figures 10 to 12 that the Weber A4 model provides reliable predictions in the dilute-phase (high air flow) zone only. The model provides 
significant under-predictions in dense-phase (low velocity) region. For the $69 \mathrm{~mm}$ I.D. x $168 \mathrm{~m}$ long pipe, the newly developed model provides better prediction in dense-phase than the Setia et al. [16] model. At the high velocity zone, both the new and Setia et al. [16] models provide similar reliable predictions. For the $105 \mathrm{~mm}$ I.D. x $168 \mathrm{~m}$ long pipe, both the new and Setia et al. [16] models provide similar predictions at very dense-phase condition. For the 69 mm I.D. x 554 $\mathrm{m}$ long pipe, the new model provides slight under-predictions in dense-phase. The Setia et al. model [16] has provided over-predictions, whose absolute values (deviation from the experimental conveying characteristics) are more than that predicted by the new model. Overall, it can be observed that the new model and the Setia et al. [16] model provide similar accuracy under scale-up conditions, with the new model providing some improvements in very densephase region. The Setia et al. [16] model provided better reliable predictions (covering both the dense- and dilute-phase conditions) compared to the other existing models (e.g. models that are in the format of equation 2 and 3) $[9,10,15]$. The new model is able to predict with similar reliability as Setia et al. [16]. This signifies the importance of using particle and actual gas velocity in the model of solids friction factor. The results obtained using the new modeling technique have demonstrated potential towards better representing the flow mechanism and to develop a more fundamental based model.

\section{Conclusion}

The results of numerical modelling performed using Runge-Kutta-Fehlberg (RKF45) method to solve the governing equations of flow for fluidized dense-phase pneumatic conveying of fly ash 
for different air flow rates and fluidized bulk densities have shown that the particle and actual gas velocities and the ratio of the two velocities increase in the direction of flow, while a reverse trend is apparent for the solids volumtric concentration. An existing realiable dilute-phase model for solids friction factor has been amended to address dense-phase flow condition by incorportaing model for particle to gas velocity (using solids loading ratio and dimensionless velocity) and impact and solids friction factor (using volumtric loading ratio and dimensionless velocity). The newly developed model for solids friction factor, when tested under scale-up conditions by using them to predict the pressure drops for larger and longer pipelines and by comparing the experimental and predicted pneumatic conveying characteristics, has resulted in reliable predictions. The accuracy of predictions is similar (in fact at times better in certain scaleup cases) compared to a recently developed two-layer based model, indicating that the new model has the capability to address the gradual transition of dense- to dilute-phase flow mechanisms of fine powders. The results also indicate the importance of incorporating particle and actual gas velocity terms in modeling solids friction factor. Future work should be carried out to develop reliable experimental measurement techniques for the particle velocity of fine powders under fluidized dense-phase flow condition.

\section{List of symbols and abbreviations}

$\begin{array}{ll}A & \text { Cross sectional area of control volume }\left[\mathrm{m}^{2}\right] \\ B, b, c & \text { Exponents of power function } \\ B & \text { Bend loss factor }\end{array}$




\begin{tabular}{|c|c|}
\hline C & Particle velocity $[\mathrm{m} / \mathrm{s}]$ \\
\hline$D$ & Internal diameter of pipe $[\mathrm{m}]$ \\
\hline$d_{p}$ & Particle diameter $[\mu \mathrm{m}]$ \\
\hline$d_{50}$ & Median particle diameter $[\mu \mathrm{m}]$ \\
\hline$F r=V /(g D)^{0.5}$ & Froude number of flow \\
\hline$F r_{i}=V_{i} /(g D)^{0.5}$ & Froude number of flow at the beginning of pipe (initial Froude number) \\
\hline$F r_{s}=w_{f o} / \sqrt{g d_{50}}$ & Particle Froude number \\
\hline$F_{a}$ & Frictional force due to air phase $[\mathrm{N}]$ \\
\hline$F_{S}$ & Frictional force due to solids phase $[\mathrm{N}]$ \\
\hline$f_{a}$ & Frictional force per unit volume due to air phase $\left[\mathrm{N} / \mathrm{m}^{3}\right]$ \\
\hline$f_{s}$ & Frictional force per unit volume due to solids phase $\left[\mathrm{N} / \mathrm{m}^{3}\right]$ \\
\hline$g$ & Acceleration due to gravity $\left[\mathrm{m} / \mathrm{s}^{2}\right]$ \\
\hline$K$ & Constant of power function \\
\hline$L$ & Length of horizontal pipe or test section $[\mathrm{m}]$ \\
\hline$L_{v}$ & Length of vertical pipe or test section $[\mathrm{m}]$ \\
\hline$m_{f}, m_{a}$ & Mass flow rate of air $[\mathrm{kg} / \mathrm{s}]$ \\
\hline$m_{s}$ & Mass flow rate of solids $[\mathrm{kg} / \mathrm{s}]$ \\
\hline$m^{*}=m_{s} / m_{a}$ & Solids loading ratio \\
\hline$N$ & Number of bends \\
\hline$P$ & Pressure $[\mathrm{Pa}]$ \\
\hline$\Delta P$ & Pressure drop through a straight horizontal pipe or pipe section $[\mathrm{Pa}]$ \\
\hline$\Delta P_{\text {accel }}$ & Pressure drop due to initial acceleration $[\mathrm{Pa}]$ \\
\hline
\end{tabular}




\begin{tabular}{|c|c|}
\hline$\Delta P_{b}$ & Pressure drop due to the bends $[\mathrm{Pa}]$ \\
\hline$\Delta P_{V}$ & Pressure drop due to the verticals $[\mathrm{Pa}]$ \\
\hline$u_{a}$ & Actual gas velocity $[\mathrm{m} / \mathrm{s}]$ \\
\hline$u_{s}$ & Particle velocity $[\mathrm{m} / \mathrm{s}]$ \\
\hline$V$ & Superficial air or gas velocity $[\mathrm{m} / \mathrm{s}]$ \\
\hline$V_{a}=m_{a} / \rho_{a}$ & Volumetric flow rate of air $\left[\mathrm{m}^{3} / \mathrm{s}\right]$ \\
\hline$V_{s}=m_{s} / \rho_{f l}$ & Volumetric flow rate of solids $\left[\mathrm{m}^{3} / \mathrm{s}\right]$ \\
\hline$V L R=\left\{\left(m_{s} / \rho_{s}\right) /\left(m_{f} / \rho_{a}\right)\right\}$ & Volumetric loading ratio \\
\hline$w_{f o}$ & Free settling velocity of an isolated particle $[\mathrm{m} / \mathrm{s}]$ \\
\hline$w_{f o} / V$ & Dimensionless velocity \\
\hline$\rho, \rho_{a}$ & Density of air $\left[\mathrm{kg} / \mathrm{m}^{3}\right]$ \\
\hline$\rho_{s}$ & Particle density $\left[\mathrm{kg} / \mathrm{m}^{3}\right]$ \\
\hline$\rho_{b}$ & Loose-poured bulk density $\left[\mathrm{kg} / \mathrm{m}^{3}\right]$ \\
\hline$\rho_{f l}$ & Fluidized bulk density $\left[\mathrm{kg} / \mathrm{m}^{3}\right]$ \\
\hline$\lambda_{f}$ & Air/gas only friction factor \\
\hline$\lambda_{s}$ & Solids friction factor through straight pipe \\
\hline$\lambda_{\mathrm{s}}^{*}$ & Impact and friction factor for solids \\
\hline$\varepsilon_{a}=V_{a} /\left(V_{a}+V_{s}\right)$ & Volume fraction of air \\
\hline$\varepsilon_{s}=V_{s} /\left(V_{a}+V_{s}\right)$ & Volume fraction of solids \\
\hline
\end{tabular}




\section{References}

[1] G.E. Klinzing, R.D. Marcus, F. Rizk and L.S. Leung, Pneumatic Conveying of Solids - A Theoretical and Practical Approach, Chapman \& Hall, 1997.

[2] S.S. Mallick, PhD Dissertation, Modelling dense-phase pneumatic conveying of powders, University of Wollongong, 2009.

[3] R. Pan, Material properties and flow modes in pneumatic conveying, Powder Technology, 104(2) (1999) 157-163.

[4] W. Barth, Strömungsvorgänge beim transport von festteilchen und flüssigkeitsteilchen in gasen, Chemie - Ing. - Techn, 30 (3) (1958) 171-180.

[5] M. Weber, Principles of hydraulic and pneumatic conveying in pipes, Bulk Solids Handling, 1 (1981) 57-63.

[6] R. Pan, P.W. Wypych, Scale up procedures for pneumatic conveying design, Powder Handling and Processing 4 (2) (1992) 167-172.

[7] M.G. Jones, K.C.Williams, Solids friction factors for fluidized dense phase conveying, Particulate Science and Technology, 21 (2003) 45-56.

[8] R. Pan, P.W. Wypych, Dilute and dense phase pneumatic conveying of fly ash, The proceedings of 6th International Conference on Bulk Materials Storage and Transportation, Wollongong, NSW, Australia, (1998) 183-189.

[9] G. Setia, S.S. Mallick, P.W. Wypych, On Improving Solid Friction Factor Modelling for Fluidized Dense-Phase Pneumatic Conveying Systems, Powder Technology 257 (2014) 88-103. 
[10] G. Setia and S.S. Mallick, Modelling Fluidized Dense-Phase Pneumatic Conveying of Fly Ash, Powder Technology, 270 (2015) 39-45.

[11] P.K. Swamee and A.K. Jain, Explicit equations for pipe-flow problems, Journal of the Hydraulics Division, ASCE. 102 (1976) 657-664.

[12] B. Mi and P.W. Wypych, Pressure drop prediction in low-velocity pneumatic conveying, Powder Technology, 81 (1994) 125-137.

[13] B. Mi and P.W. Wypych, Investigations into wall pressure during slug-flow pneumatic conveying, Powder Technology, 84 (1995) 91-98.

[14] R. Pan and P.W. Wypych, Pressure Drop and Slug Velocity in Low-Velocity Pneumatic Conveying of Bulk Solids, Powder Technology, 94 (1997) 123-132.

[15] P.W. Wypych, O.C. Kennedy and P.C. Arnold, The future potential of pneumatically conveying coal through pipelines, Bulk Solids Handling, 10 (1990) 421-427.

[16] G. Setia, S.S. Mallick, P.W. Wypych and R. Pan, Modeling solids friction factor for fluidized dense-phase pneumatic transport of powders using two layer flow theory, Powder Technology, 294 (2016) 80-92.

[17] N. Behera, V. K. Agarwal, M.G. Jones and K. Kenneth C. Williams, Modeling and analysis for fluidized dense phase conveying of powders, Particulate Science and Technology, 31 (2013) 136-146.

[18] N. Behera, V. K. Agarwal, M.G. Jones and K. Kenneth C. Williams, Modeling and analysis for fluidized dense phase conveying including particle size distribution, Powder technology, 235 (2013) 386-94. 
[19] N. Behera, V. K. Agarwal, M.G. Jones and K. Kenneth C. Williams, CFD modeling and analysis of dense phase pneumatic conveying of fine particles including particle size distribution. Powder Technology. 244 (2013) 30-37.

[20] Wang Wei, Guan Qingliang, Wu Yuxin, Yang Hairui, Zhang Jiansheng and Lu Junfu, Experimental study on the solid velocity in horizontal dilute phase pneumatic conveying of fine powder, Powder Technology, 212 (2011) 403-409.

[21] K. Li, S.B. Kuang, R.H. Pan, A.B. Yu, Numerical study of horizontal pneumatic conveying: Effect of material properties. Powder Technology. 251 (2014) 15-24.

[22] E. Fehlberg, Low-order classical Runge-Kutta formulas with step size control and their application to some heat transfer problems, NASA Technical Report, 315 (1969).

[23] L. Shampine, H. Watts and S. Davenport, Solving Non-stiff ordinary differential equations - the state of the art, SIAM Review, 18 (1976) 376-411.

[24] G.E. Klinzing, C.A. Myler, A. Zaltash, A simplified correlation for solids friction factor in horizontal conveying systems based on Yang's unified theory. Powder Technology. 58 (1989) 187-193.

[25] J. Hong, Y.S. Shen, Flow characteristics of high density continuous conveying of solids. Engineering Chemistry and Metallurgy. 15 (1994) 122-128 (in Chinese).

[26] A. Rautiainen, G. Stewart, V. Poikolainen, and P. Sarkomaa, 1999. An experimental study of vertical pneumatic conveying. Powder Technology, 104 (1999) 139-150.

[27] T. Bosse, L. Kleiser and E. Meiburg, 2006. Small particles in homogeneous turbulence. Physics of Fluids, 18: 027102 (2006) 1-17.

[28] N. Huberand and M. Sommerfeld, 1998. Modelling and numerical calculation of dilutephase pneumatic conveying in pipe systems. Powder Technology, 99 (1998) 90-101. 
[29] A.J. Chambers and R.D. Marcus, 1986. Pneumatic conveying calculations. In the proceedings of $2^{\text {nd }}$ International Conference on Bulk Materials Storage and Transportation, Wollongong, Australia, 7-9 July, 2006, pp. 49-52.

[30] S.B. Kuang, R. P. Zou, R. H.Pan and A. B. Yu, 2012, Gas solid flow and energy dissipation in inclined pneumatic conveying, Ind Eng Chem Res, 51, 14289-14302. 


\section{Highlights:}

- Fly ash was conveyed from fluidized dense- to dilute-phase.

- Flow governing equations were solved by Runge-Kutta-Fehlberg (RKF45) method.

- Ratio of particle to actual air velocity increased with along flow direction.

- A dilute-phase model is amended to dense-phase using particle to air velocity.

- New model has provided reliable scale-up predictions under dense-phase. 
Schematic diagram of the $69 \mathrm{~mm}$ I.D. x $168 \mathrm{~m}$ long pipeline is shown in Figure 1.

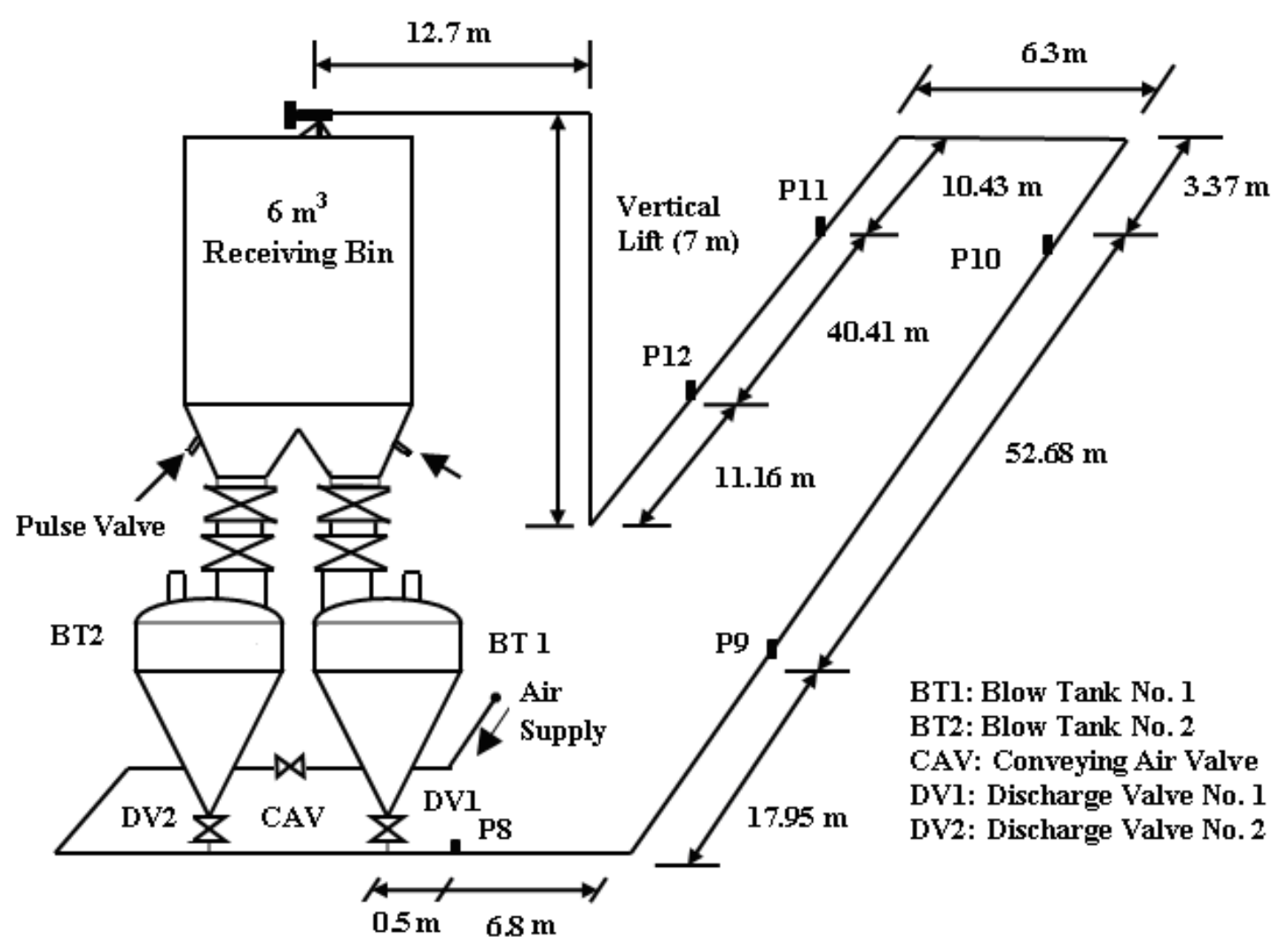

Figure 1: Layout of the $69 \mathrm{~mm}$ I.D. x $168 \mathrm{~m}$ test rig (for fly ash) 


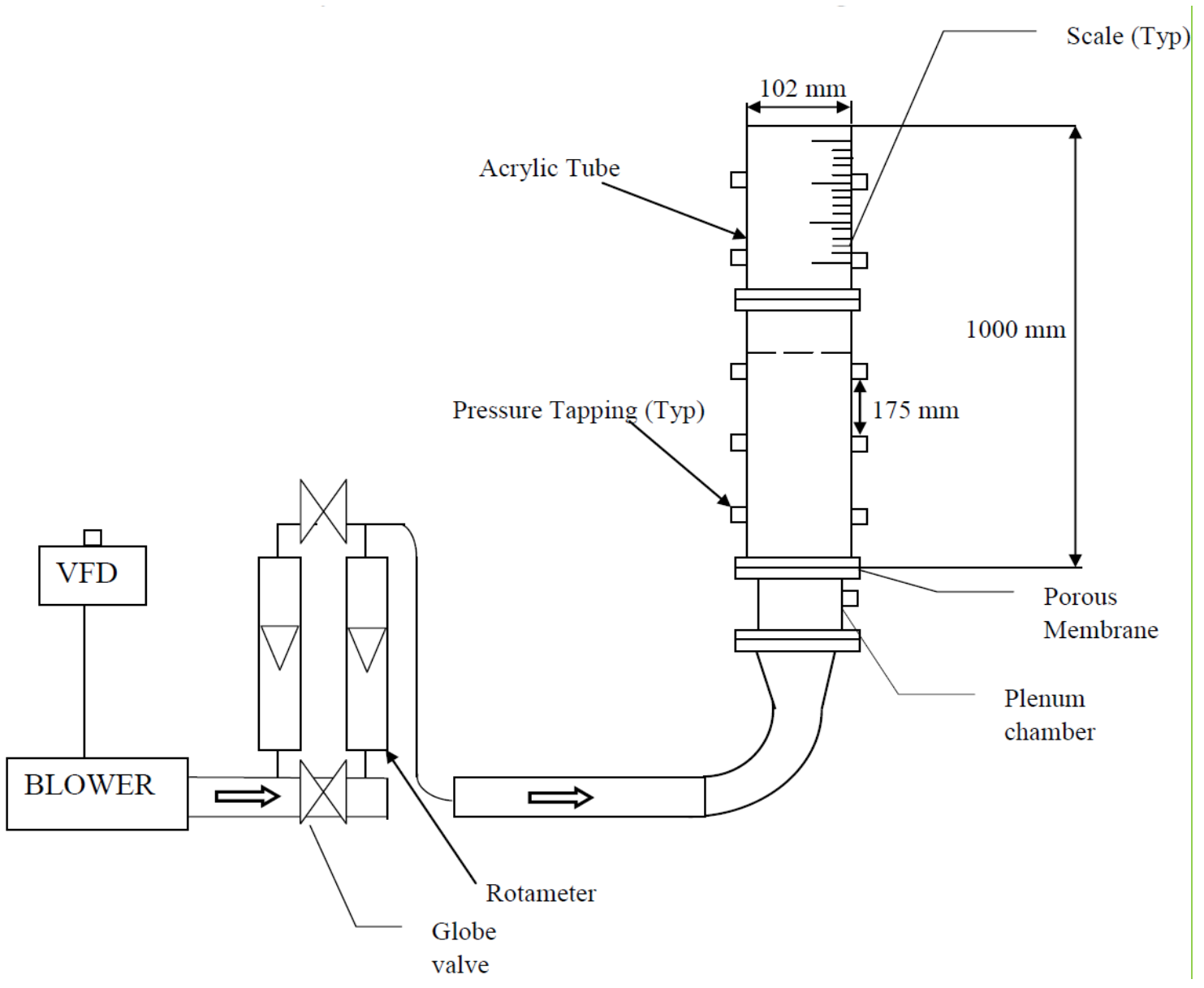

Figure 2: Fluidization and de-aeration chamber 


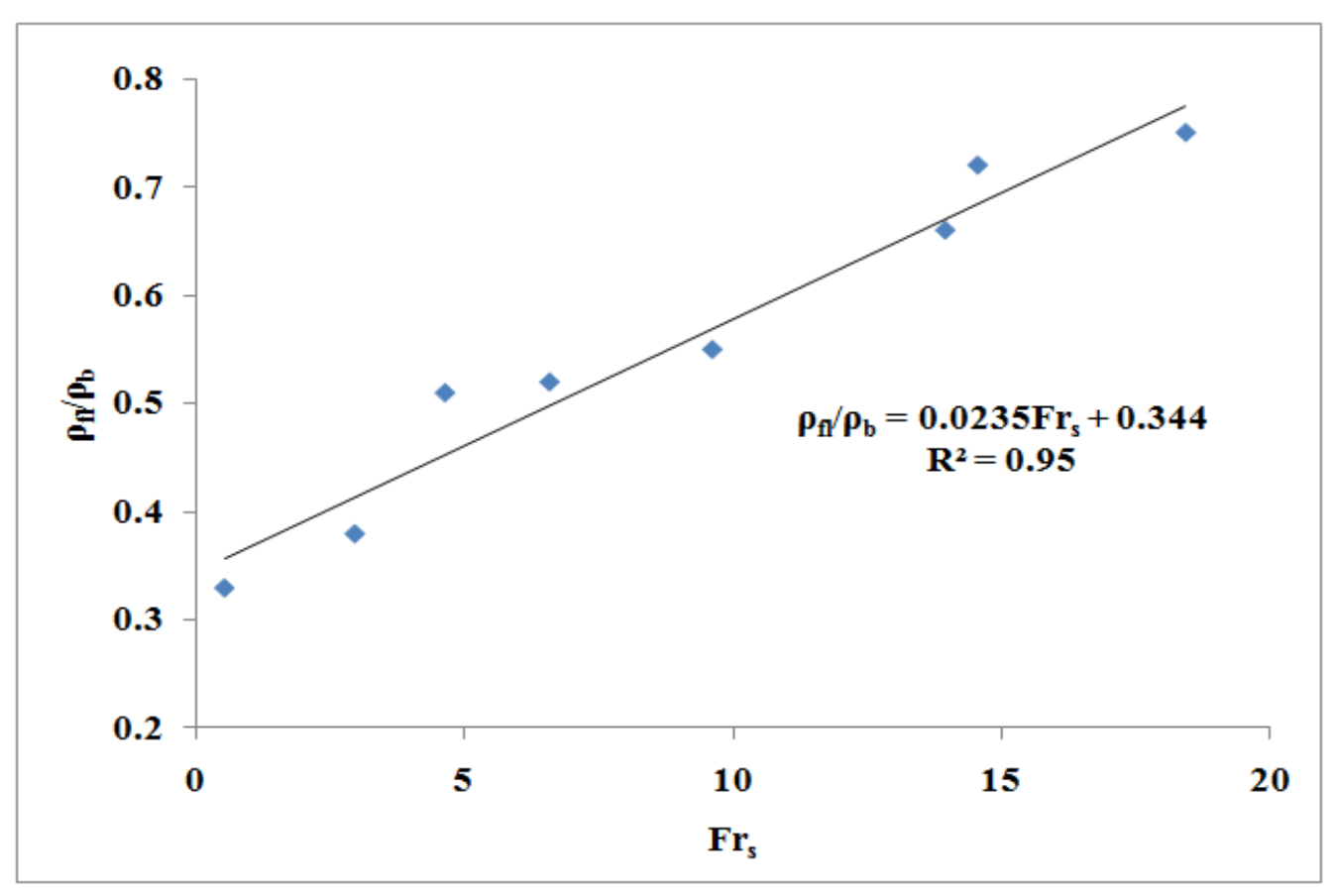

Figure 3: Model development for fluidized bulk density of fly ash 


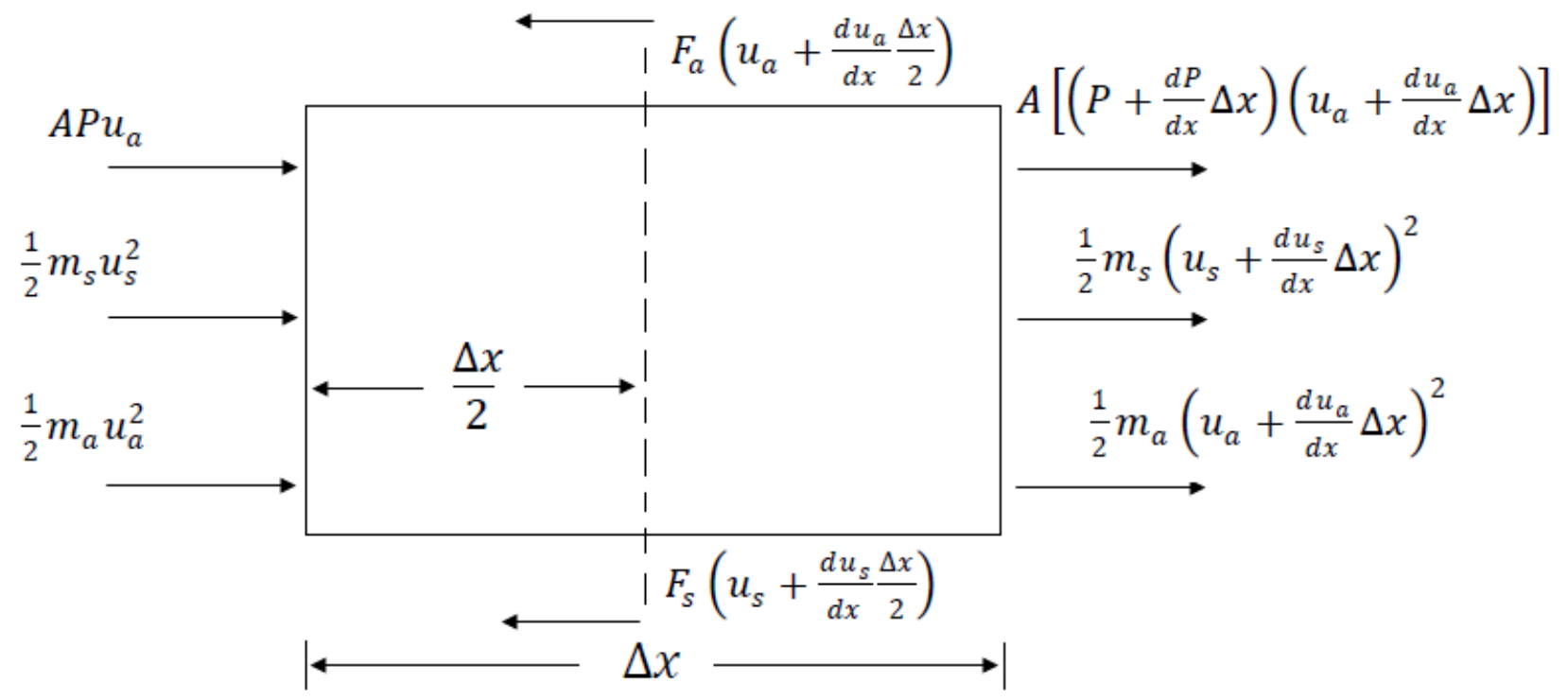

Figure 4: Energy interactions across a control volume

(a) 


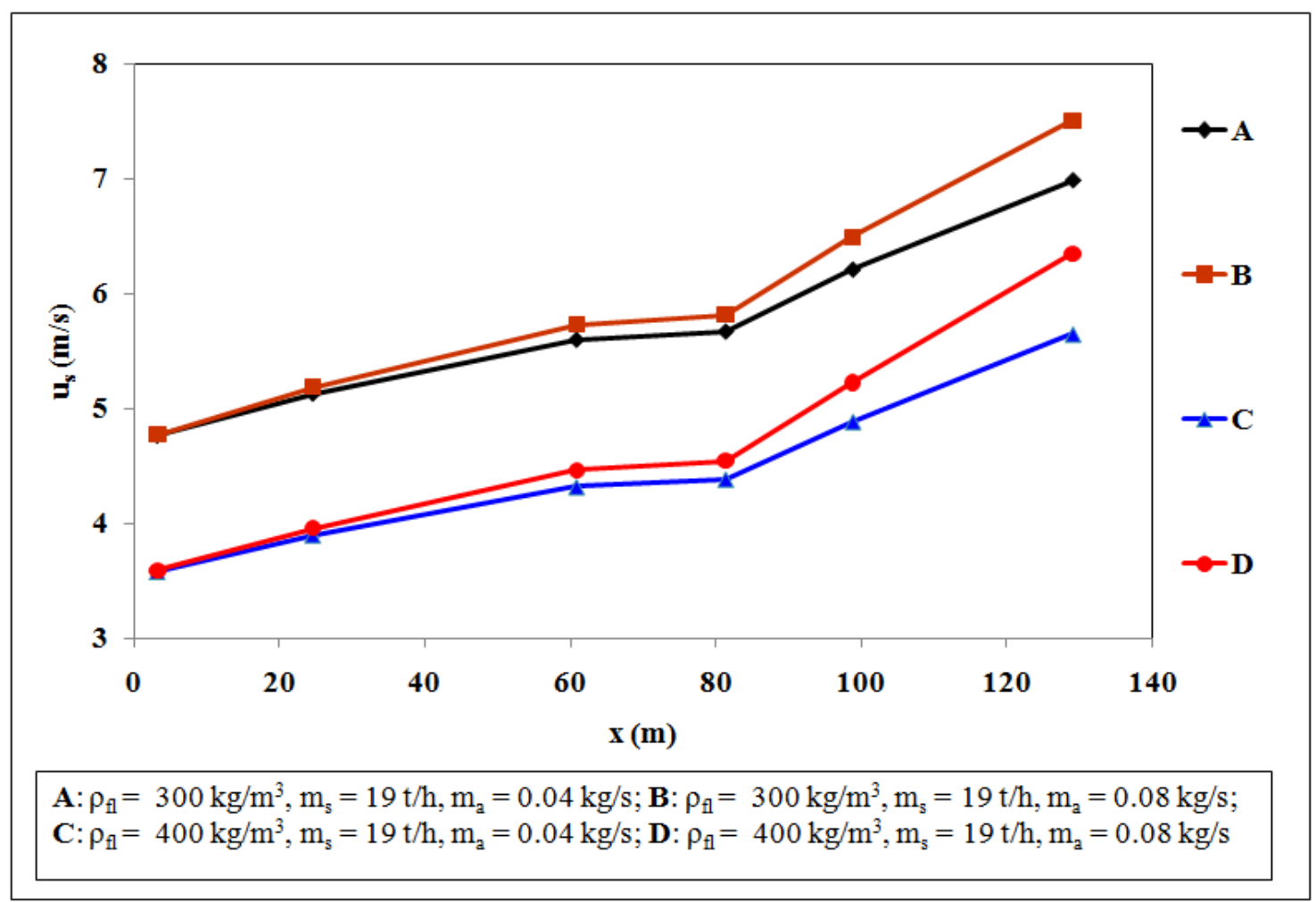

Figure 5: Variation of dune velocity for different air flows and fluidized bulk densities along the flow direction 


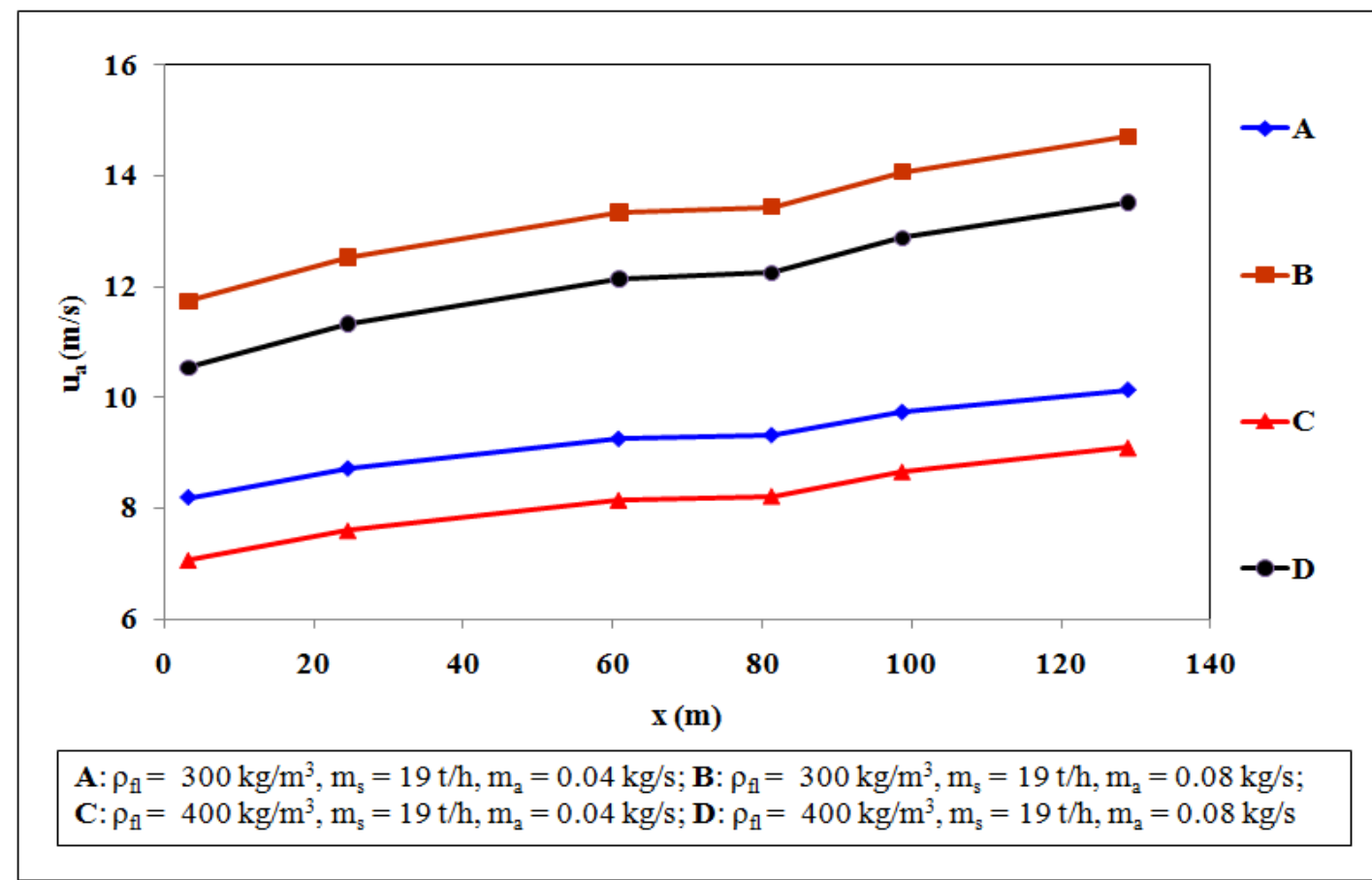

Figure 6: Variation of actual air velocity for different air flows and fluidized bulk densities along the flow direction 


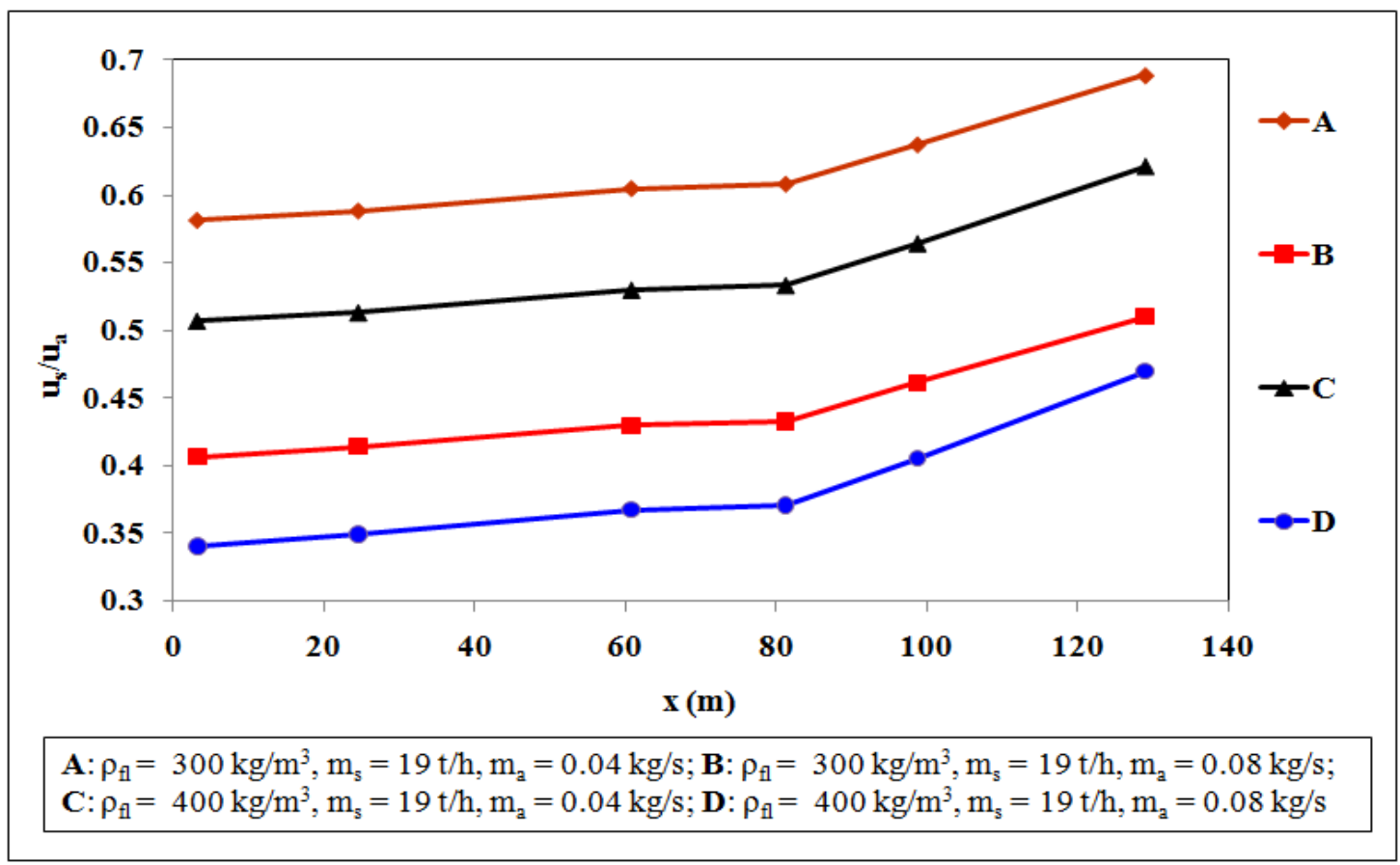

Figure 7: Variation of ratio of dune to actual air velocity for different air flows and fluidized bulk densities along the flow direction 


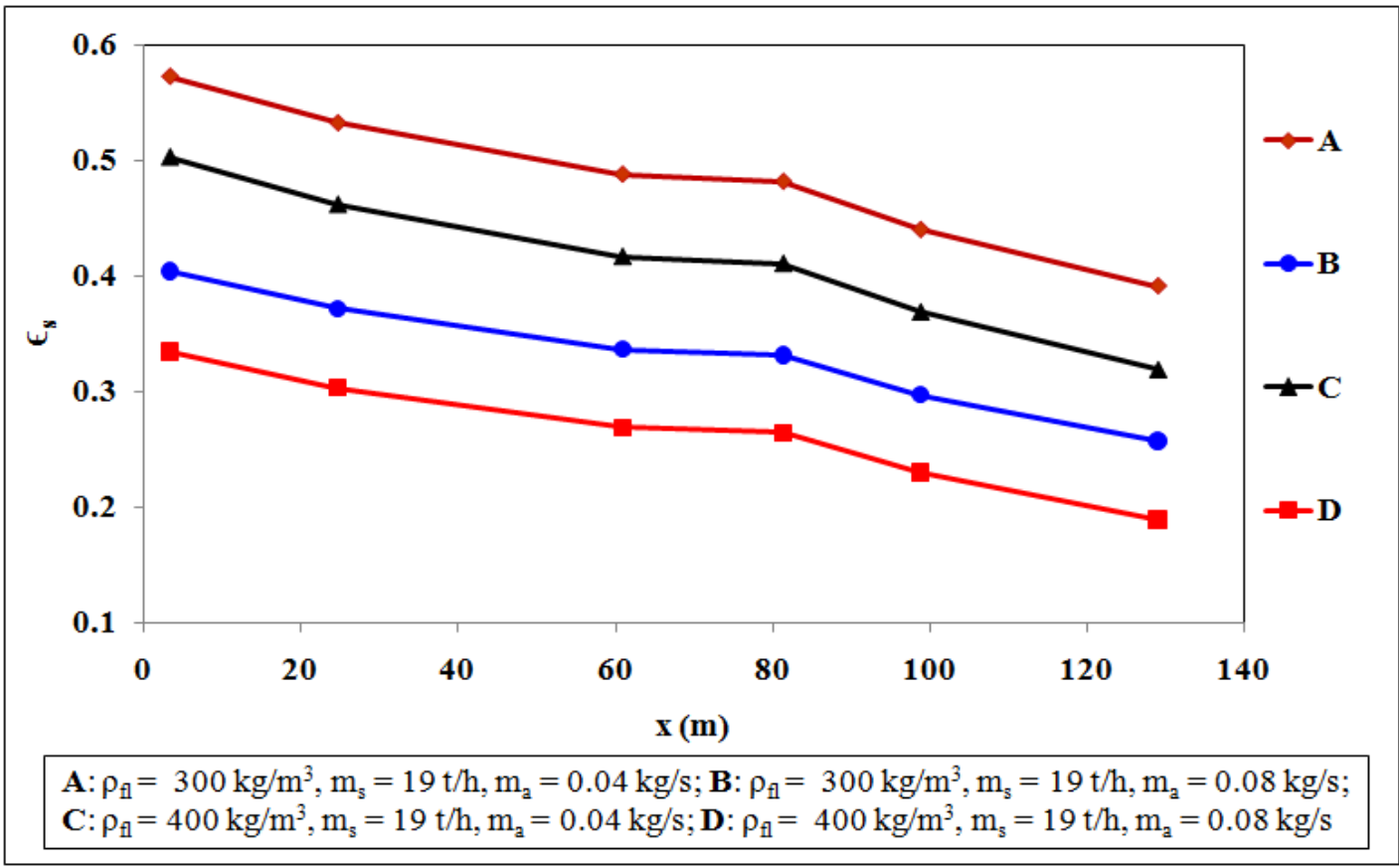

Figure 8: Variation of solids volumetric concentration for different air flows and

fluidized bulk densities along the flow direction 


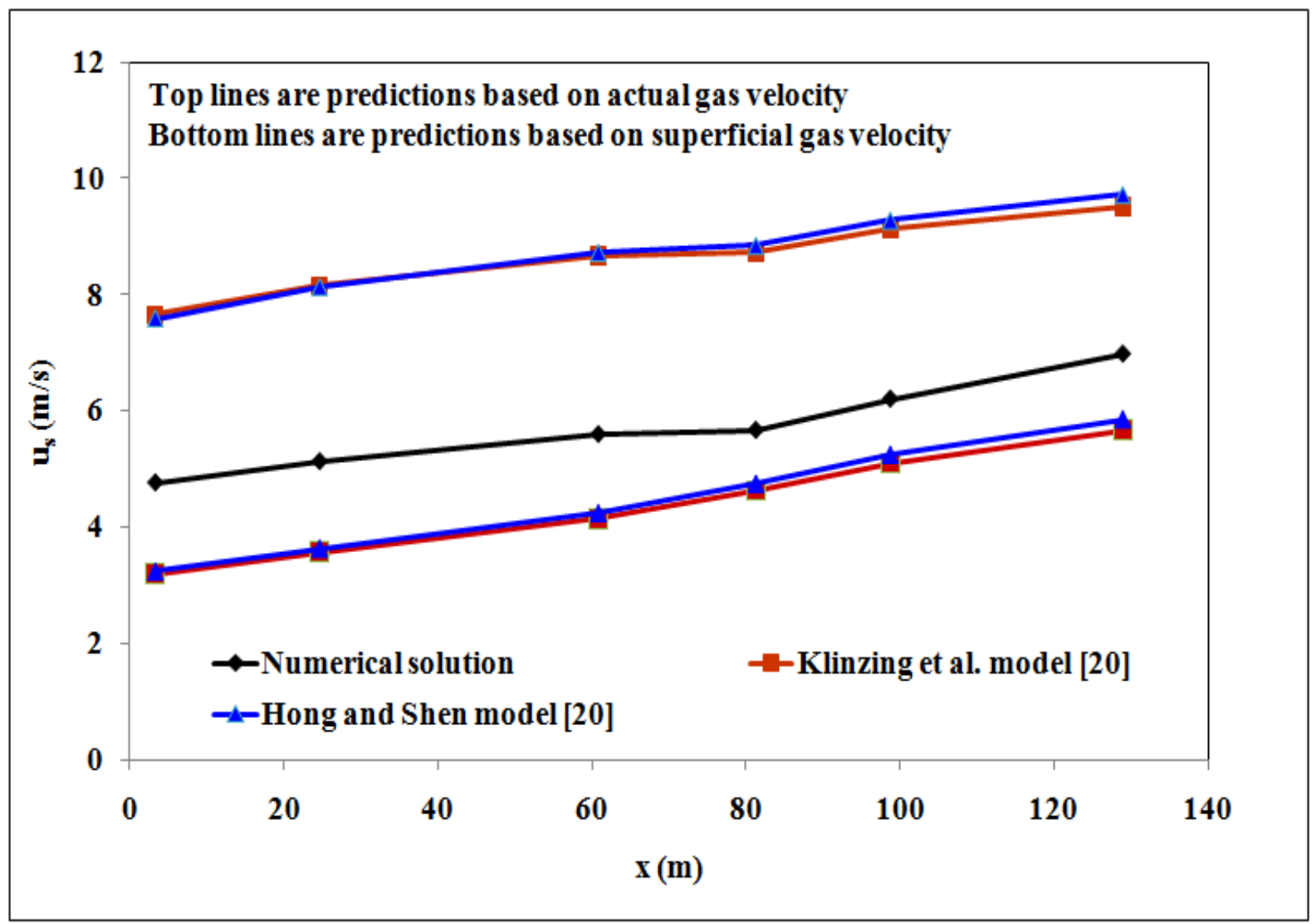

Figure 9: Comparison of prediction of dune velocity, numerical versus model predictions,

$$
\mathrm{m}_{\mathrm{s}}=19 \mathrm{t} / \mathrm{h}, \mathrm{m}_{\mathrm{a}}=0.04 \mathrm{~kg} / \mathrm{s}, \rho_{\mathrm{fl}}=300 \mathrm{~kg} / \mathrm{m}^{3}
$$




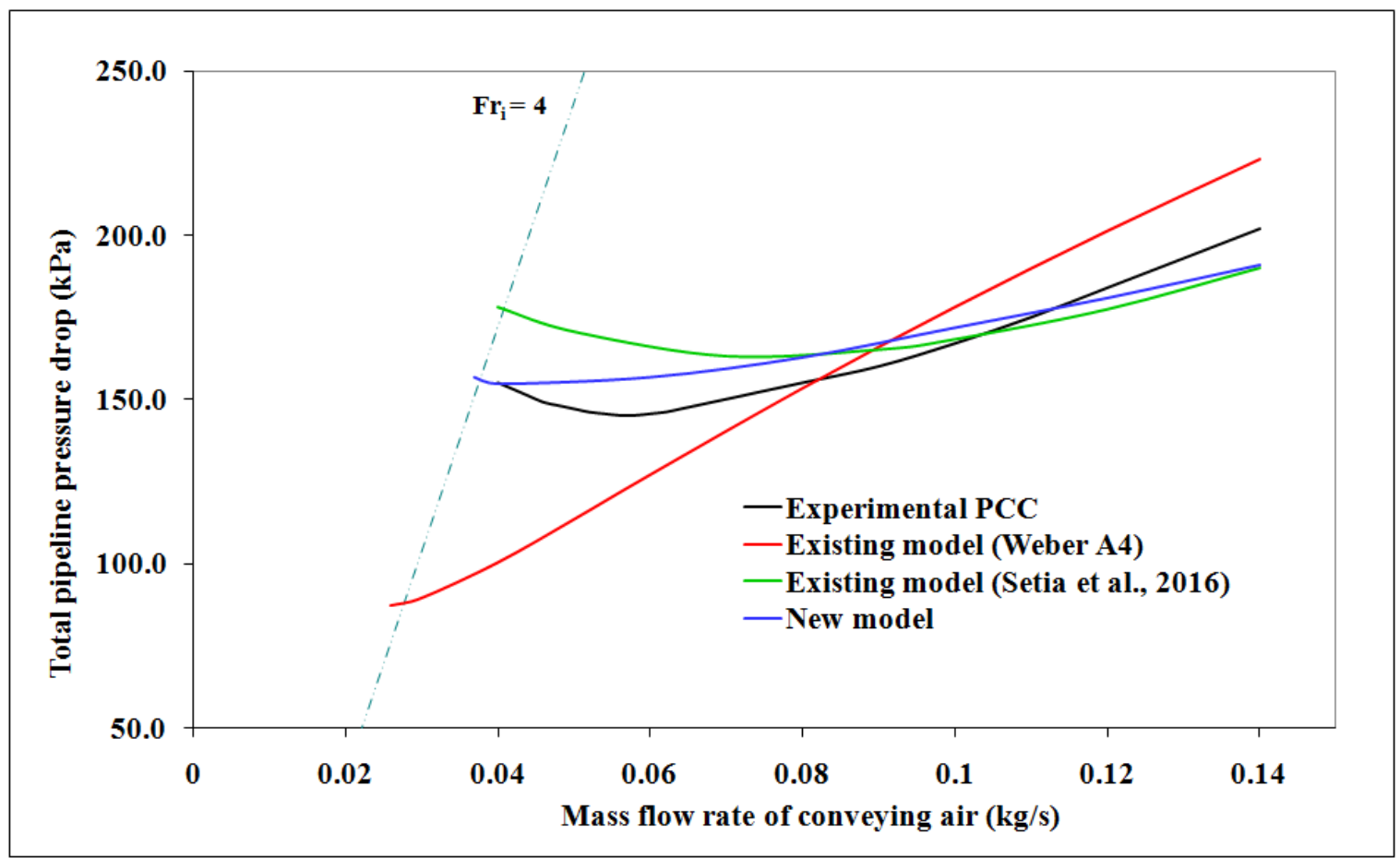

Figure 10: Scale-up evaluation for solids friction factor model

$$
\mathrm{m}_{\mathrm{s}}=19 \mathrm{t} / \mathrm{h}, \mathrm{D}=69 \mathrm{~mm}, \mathrm{~L}=168 \mathrm{~m}
$$




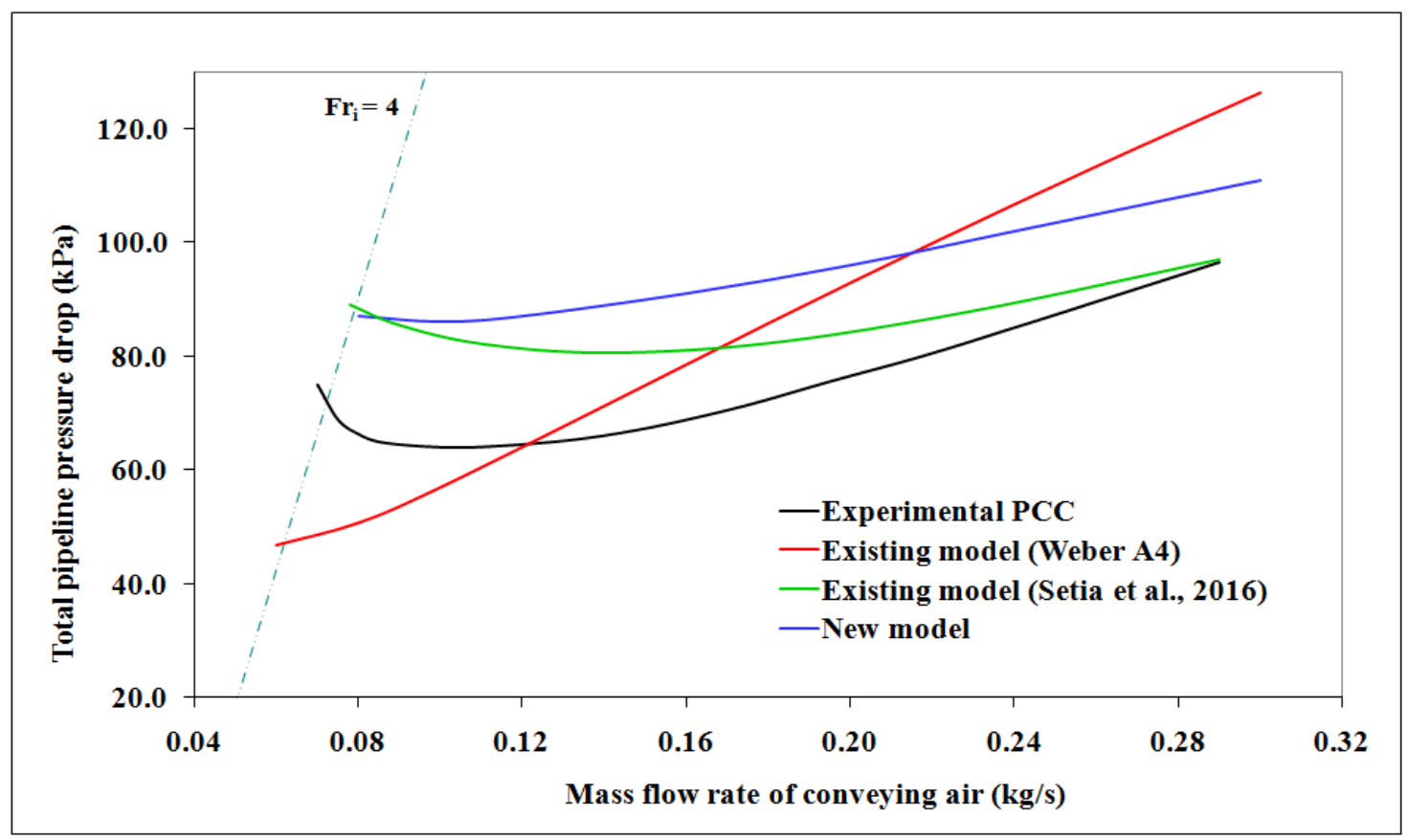

Figure 11: Scale-up evaluation for solids friction factor model

$$
\mathrm{m}_{\mathrm{s}}=28 \mathrm{t} / \mathrm{h}, \mathrm{D}=105 \mathrm{~mm}, \mathrm{~L}=168 \mathrm{~m}
$$




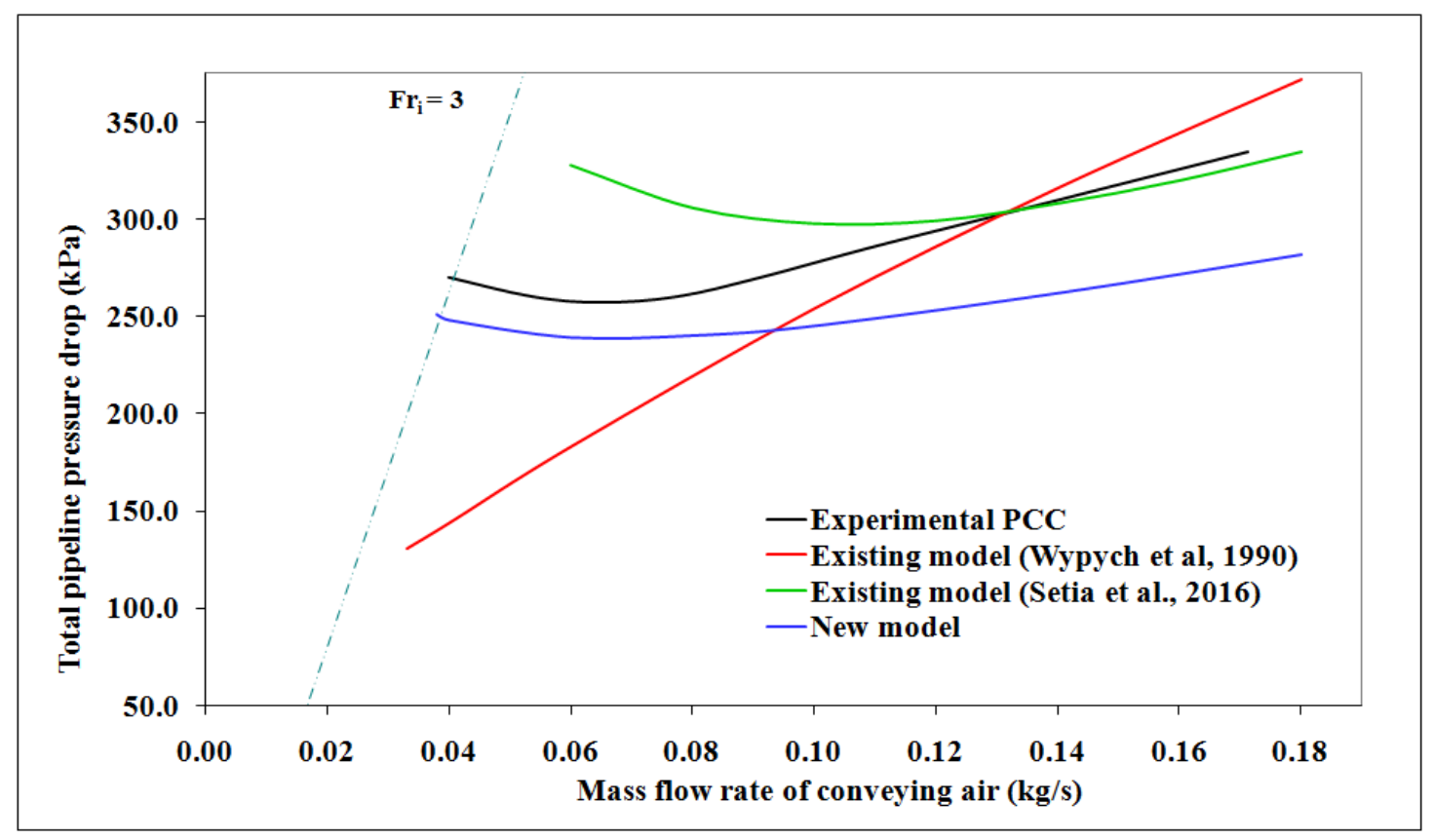

Figure 12: Scale-up evaluation for solids friction factor model

$$
\mathrm{m}_{\mathrm{s}}=11 \mathrm{t} / \mathrm{h}, \mathrm{D}=69 \mathrm{~mm}, \mathrm{~L}=554 \mathrm{~m}
$$


Table 1: Physical properties of the fly ash conveyed

\begin{tabular}{|c|c|c|c|c|c|c|c|c|}
\hline $\begin{array}{c}\text { Fly ash } \\
\text { no. }\end{array}$ & $\begin{array}{c}\mathbf{d}_{\mathbf{1 0}} \\
(\boldsymbol{\mu} \mathbf{m})\end{array}$ & $\begin{array}{c}\mathbf{d}_{\mathbf{5 0}} \\
(\boldsymbol{\mu \mathbf { m }})\end{array}$ & $\begin{array}{c}\mathbf{d}_{\mathbf{9} 0} \\
(\boldsymbol{\mu \mathbf { m }})\end{array}$ & $\begin{array}{c}\mathbf{\rho}_{\mathbf{s}} \\
\left(\mathbf{k g} / \mathbf{m}^{\mathbf{3}}\right)\end{array}$ & $\begin{array}{c}\boldsymbol{\rho}_{\mathbf{b}} \\
\left(\mathbf{k g} / \mathbf{m}^{\mathbf{3}}\right)\end{array}$ & $\begin{array}{c}\mathbf{w}_{\mathbf{f}} \\
(\mathbf{m} / \mathbf{s})\end{array}$ & $\begin{array}{c}\mathbf{D} \\
(\mathbf{m m})\end{array}$ & $\begin{array}{c}\mathbf{L} \\
(\mathbf{m})\end{array}$ \\
\hline 1 & 5 & 30 & 145 & 2300 & 700 & 0.06 & 105 & 168 \\
& & & & & & & 69 & 554 \\
\hline
\end{tabular}


Table 2: Physical properties of different fly ash samples for fluidization and deaeration tests

\begin{tabular}{|c|c|c|c|c|c|c|c|c|}
\hline Fly ash & $\mathbf{d}_{\mathbf{1 0}}$ & $\mathbf{d}_{\mathbf{5 0}}$ & $\mathbf{d}_{\mathbf{9 0}}$ & $\boldsymbol{\rho}_{\mathbf{s}}$ & $\boldsymbol{\rho}_{\mathbf{b}}$ & $\mathbf{w}_{\mathbf{f o}}$ & $\boldsymbol{\rho}_{\mathbf{f l}} / \mathbf{\rho}_{\mathbf{b}}$ & $\mathbf{F r}_{\mathbf{s}}$ \\
\hline $\mathbf{n o .}$ & $(\boldsymbol{\mu \mathbf { m }})$ & $(\boldsymbol{\mu m})$ & $(\boldsymbol{\mu m})$ & $\left(\mathbf{k g} / \mathbf{m}^{\mathbf{3}}\right)$ & $\left(\mathbf{k g} / \mathbf{m}^{\mathbf{3}}\right)$ & $(\mathbf{m} / \mathbf{s})$ & & $\mathbf{w}_{\mathbf{f o}} / \sqrt{\mathbf{g d}} \mathbf{5 0}$ \\
\hline 2 & 42 & 139 & 316 & 2015 & 848 & 0.68 & 0.75 & 18.42 \\
\hline 3 & 23 & 102 & 255 & 2014 & 839 & 0.46 & 0.72 & 14.55 \\
\hline 4 & 23 & 97 & 213 & 2018 & 830 & 0.43 & 0.66 & 13.95 \\
\hline 5 & 18 & 69 & 170 & 2025 & 818 & 0.25 & 0.55 & 9.61 \\
\hline 6 & 14 & 53 & 141 & 2032 & 804 & 0.15 & 0.52 & 6.58 \\
\hline 7 & 12 & 41 & 108 & 2030 & 780 & 0.093 & 0.51 & 4.64 \\
\hline 8 & 6 & 28 & 120 & 1999 & 710 & 0.049 & 0.38 & 2.96 \\
\hline 9 & 2 & 9 & 69 & 2051 & 683 & 0.005 & 0.33 & 0.53 \\
\hline
\end{tabular}

